\title{
The Influence Factors That Affect Thailand's Management Of Youth Reproductive Health Service
}

Sioy Anusornteerakul, Khon Kean University, Thailand Kimaporn Khamanarong, Khon Kean University, Thailand Suranart Khamanarong, Khon Kean University, Thailand Jadsada Thinkhamrop, Khon Kean University, Thailand

\begin{abstract}
The management of reproductive health service for youth has become an important issue during the recent year. However, management has no clear idea about the influential factors of concern to. In this paper, we will discuss these influence factors that affect the management of youth reproductive healthcare service. Mixed methods were used for data collection, including qualitative methods that were conducted by in-dept interview and analyzed by binary logistic regression. According to the analysis, we found six factors that affect the management of reproductive health service, including (1) personal expense, (2) communication within the family, (3) fear of parents' reactions, (4) the bureaucratic process of healthcare services, (5) the limitation of healthcare services, and (6) healthcare providers. Then, we reduced the six factors into three group factors that we call three systems to explain these important factors that are of concern to management of reproductive health service. These include the personnel system, service system, and the family support system.
\end{abstract}

Keywords: Reproductive health service, Influence factor, Adolescent, Youth

\section{INTRODUCTION}

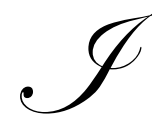
$\mathrm{n}$ recent years, the reproductive health of youth has become an important issue. Twenty percent of the world population are between 10-19 years old, and 85 percent of them are in developing countries (Ruangkanchanasetr and Mahachoklertwattana, 2006). Furthermore, world population estimates have found that, in year 2010, the number of youth will increase 22.79, and by the year 2015, they will have increased by 26.13 percent (Kamnaunsilpa, 2004). Thus, the youth health problem is a significant issue and they are an important resource. Every country make it a priority to develop a government policy to protect youth health, because they are future human capital. Human capital refers to the full range of knowledge, skills, and abilities that an individual can use to produce a given set of outcomes (Hitt, Bierman, Shimizu, and Kochhar, 2001). And then, human capital is likely to provide unique advantages to each country, as it relates to the launching of specific and observable competitive moves around the world.

Every country must face similar problems with respect to the reproductive health of youth, such as no sexual prevention which leads to problems such as unplanned pregnancy, unsafe abortion, and sexual infection including HIV/AIDS. More than 10 percent of babies are born to women under 18 years old, a rate that doubles among moms between 18-25. In addition, abortions occur at a rate of 40-60 million people per year, which includes those who die from unsafe abortions (approximately 70,000 people per year), 90 percent of whom live in developing countries (WHO, 2007a). In developing countries, hospital records indicate that approximately 36 to 38 percent of women who are treated for complications of abortion are under 20 years old (Olukoya, Kaya, Ferguson and AbouZahr, 2001). Furthermore, at least one in 10 abortions worldwide are performed on women between the ages of 15-19 years old (WHO, 2007b). 
Since 1990, the United States Government cited concerns within the healthcare system to encourage both local and national agencies to participate in solving this problem by evaluating the alternative choices for management, requirements and feasibility studies of the healthcare service system, and an emphasis in high school service (Lear, 2002). The concept of reproductive healthcare service at youth friendly clinics in Europe and the United States will reduce the problem of unplanned pregnancies and sexual problems among youth (Long, et al, 2003). In addition, the Indonesian government has tried to solve this problem with the concept of family and community centers that make use of peer educator volunteers, social service officers, non government organization (NGO), and local agencies. However, the approach is still unsuccessful (Hull, Hasmi and Widyantoro, 2004).

In Thailand, the maintenance of reproductive health is a problem, since young people are engaging in sexual activity at a younger age. A recent study found that 10 percent of girls between 13-15 years old have had sex without protection (Deepasert, 2006). In addition, young people must learn about sex from their friends or through the media, such as the Internet, television, and movies. It appears that parents are failing to discuss sex with their daughters. In addition, youth find it an inconvenience to talk with their families about the subject (Creel and Perry, 2002).

In addition, $46 \%$ of young women who terminated pregnancies were under 20 (Warakamin, Boonthai and Tangcharoensathien, 2004), and $61.3 \%$ of illegal abortions performed outside hospitals were among women younger than 24 , and $29.9 \%$ of those were under 20 . More than $24 \%$ of illegal abortions were performed on students (Intaraprasert and Pattachai, 2006), with more than 6,000 young women per year experiencing complications (Kanchanajitra et al, 2004). The most sensitive issues associated with pregnant students are unplanned pregnancies and unsafe abortions. Many students do not have access to reproductive healthcare services, and the clinics that do exist are limited in the area of youth health. A number of organizations have sought to provide adolescent-friendly services to improve access to healthcare, yet only a few programs have devised ways to systematically assess the quality of the services (Dickson, Ashton and Smith, 2007).

However, reproductive and sexual healthcare service, especially in hospitals, still lacks service quality, especially in hospitals. Adolescents or young unmarried women face barriers to accessing service and information (Yongpanichkul, 2007). The reproductive health department of Thailand's Ministry of Public Health has worked with this problem and developed a universal hospital policy hospitals that calls for the establishment a "friend corner." However, a recent evaluation revealed that the clinic failed to meet the needs of youth with reproductive health problems due to several obstacles including difficulties related to service access, confidentiality, and limitation of services that are provided at the clinics (Reproductive Health Division, 2006). Therefore, there is an urgent need to solve the problem of reproductive health service and to provide healthcare services that meet the needs of youth. Such an approach is crucial to fight the battle against unmarried youth pregnancies and unsafe abortions.

As mentioned above, it is evident that the government has no clear idea for management and set up of reproductive health service. The goal of this paper is to provide an understanding about the factors that influence management of reproductive health service, which can be a benefit to government agencies around the world.

\section{RESEARCH METHODOLOGY}

The study was conducted in the Northeast region of Thailand. Mixed methodology was employed for data collection and data analysis in both qualitative and quantitative methods to ensure that no single aspect biased the data collection. The sample in the qualitative method consisted of female youth in a government vocational school and a private school. Out-of-wedlock pregnancy among female adolescents is a sensitive issue that is considered to be a social stigma. Participants would not disclose their condition and could not be formally contacted and randomly selected. Therefore, the participants were selected with a snowball technique to include those who were introduced by their teachers and friends and who had personally experienced unplanned pregnancies. Other participants were willing to discuss the unplanned pregnancy of a close friend. There were 33 participants in this phase. Face-to-face, in-depth interviews were conducted about the youth's lifestyles, reproductive healthcare service needs, and utilization. During the quantitative method, a questionnaire was provided to 417 participants, and the sample size 
was estimated by Yamane's (1973) formula. Content analysis was obtained through face-to-face in-depth interviews, and 126 variables involved in reproductive health service utilization among school youth were identified. The 126 variables were reduced and grouped as factors by factor analysis. These variables served as the basis of a questionnaire with four subscales. The reliability of the questionnaire completed by 30 participants was 0.91 . Faceto-face interviews about lifestyles and reproductive healthcare service needs and utilization were conducted with 417 young women by using the closed-ended questionnaires that were developed from the face-to-face, in-depth interviews. Binary logistic regression with backward method were used to analyze this data.

Ethics approval was obtained from the committee for research on human subjects of the Khon Kaen University in Thailand (Number He 490529 / year 2006). Informed consent was obtained from all participants.

\section{RESULTS}

Qualitative data found that youths with unplanned pregnancies learned from their close friends who had similar problems and experiences, and took self-prescribed aborticide or visited unqualified health workers. They felt stigmatized when they visited the government health worker or medical doctor. They chose to terminate pregnancies because they did not want to quit school or did not want their parents to know about their pregnancies.

In quantitative method, we found that the adolescents were between 15 and 20 years old, with the mean age $17.9 \pm 1.4$ years old. It was found that $93.3 \%$ of youth pregnancies were unplanned and, the teen chose to terminate the pregnancy. Most of them did not disclose their pregnancies to their families and terminated it by themselves or with unskilled providers at an illegal clinic. This study found that $73.7 \%$ of adolescents with unplanned pregnancies bought an aborticide from a drugstore or visited unskilled practitioners at illegal clinics. The drugs, including suppositories, alcohol, and oral drugs for menstrual regulation, were self-administered and are shown in table 1.

Table 1 Characteristics of sample

\begin{tabular}{|c|c|c|}
\hline Characteristics & Number & Percentage \\
\hline \multicolumn{3}{|l|}{ Pregnancy } \\
\hline Accepted pregnancy & 28 & 6.7 \\
\hline Unplanned pregnancy & 389 & 93.3 \\
\hline Total & 417 & 100 \\
\hline \multicolumn{3}{|l|}{ Healthcare service used } \\
\hline Hospital/legal clinic & 111 & 26.7 \\
\hline Drugstore/illegal clinic & 306 & 73.3 \\
\hline Total & 417 & 100 \\
\hline
\end{tabular}

Table 2 showed that insufficient monetary resources, closed family communications, service limitations (e.g., long wait for services, limited service hours, insufficient services, no relaxation activities), and healthcare providers (e.g., a parent, provider and clients being close in age, unfamiliarity with healthcare providers, and male healthcare providers) increased the risk of seeking illegal and unsafe abortions. The odds ratio (ORs) were 1.63, 1.62, 1.10, and 1.15. On the other hand, fear of parents' reactions (e.g., fear of parents' knowing about their pregnancies, scolding them, not accepting their pregnancies, and feeling sorry), and the process of healthcare service (e.g., accessibility, less process of service, privacy, and secrecy) decreased the risk of seeking unsafe abortions. The odds ratios of fear of parents' reactions and the process of healthcare service factors were 0.91 and 0.88 , respectively.

The six factors influenced health service management utilization by $74.9 \%$. The six factors can grouped into three systems. The first is a personnel system comprised of personal expense, the second is the service system, comprised of the process of healthcare services, service limitations, and service healthcare providers, and the last system is the family support system, consisting of communication in the family and fear of parents' reactions. 
Table 2 Factors influencing reproductive healthcare service utilization among youth

\begin{tabular}{lccccccc}
\hline Factors & B & SE & $\begin{array}{c}\text { Wald } \\
\text { (x2-test) }\end{array}$ & $\begin{array}{c}\text { Sig } \\
\boldsymbol{p} \text {-value }\end{array}$ & $\begin{array}{c}\text { Exp(B) } \\
\text { (odds } \\
\text { ratio) }\end{array}$ & $\begin{array}{c}\text { 95\% CI Exp(B) } \\
\text { Lower } \\
\text { bound }\end{array}$ & $\begin{array}{c}\text { Upper } \\
\text { bound }\end{array}$ \\
\hline -Personal expense & & & & & & & \\
-Communication within family & 0.491 & 0.281 & 3.045 & 0.041 & 1.634 & 1.835 & 1.941 \\
-Fear of parents' reactions & 0.485 & 0.273 & 3.153 & 0.036 & 1.624 & 1.951 & 2.775 \\
-Process of healthcare service & & & & & & & \\
-Service limitations & -0.091 & 0.032 & 7.952 & 0.005 & 0.913 & 0.857 & 0.973 \\
-Healthcare providers & -0.130 & 0.057 & 5.114 & 0.024 & 0.878 & 0.785 & 0.983 \\
Constant & & & & & & & \\
& 0.092 & 0.039 & 5.573 & 0.018 & 1.097 & 1.016 & 1.184 \\
& 0.136 & 0.054 & 6.437 & 0.011 & 1.146 & 1.031 & 1.273 \\
\hline
\end{tabular}

\section{THE SYSTEMS TO SUPPORT REPRODUCTIVE HEALTHCARE SERVICE MANAGEMENT}

The most important reproductive health problems among Thai youths in this study are unplanned pregnancies and unsafe abortions. The study showed that youths were unlikely to seek care for these problems. They underutilized existing government healthcare services. Reproductive healthcare service utilization among youths who face an unplanned pregnancy can be explained by three systems as follow:

\section{1) Personnel System}

The results of this study are similar to Brindis et al (2003), which found that poverty limited access to and quality of reproductive health service, In addition, service coverage was limited. Personal resources were used for medical supplies, transportation, service charges, etc.; otherwise, the total expense for service was a satisfactory factor for the user. Most users were unwilling to pay for service, even if they had the means to do so. In setting the service charge, particularly for delivery, abortion, or reproductive healthcare service, there were many issues to consider. If the price of service was too low or service was provided free of charge, the young people perceived it as being low in quality. On the other hand, if the charge was too high, some would be unable to afford it. Therefore, fewer personal resources led to reduced access to service.

\section{2) Service System}

Health providers are the most important people to determine whether reproductive healthcare services will be successful, since they must be knowledgeable, skillful, and eager to learn new things. The youths in this study indicated that the characteristics of a good provider include understanding the school youth behavior, being able to talk comfortably with young people, sincerity, a willingness to help young people friendliness having good relationships with youths, being sensitive to youths' feelings, choosing words effectively, having a good sense of humor, being responsible with and respectful of youths' thoughts and privacy, keeping clients' information confidential, and being knowledgeable and skillful when providing counseling. Young people report that they are uncomfortable using healthcare services because of healthcare providers. They prefer to meet with female service providers who are familiar with them and who are close to their own age. This finding is consistent with previous studies (Fothergill and Ballard, 1998; Poonkhum, 2003; Fatusi, 2005). Therefore, the results of this study suggest that youth reproductive health services should be located at a site that is convenient to youths, such as a school or mall, that is easily accessible. Services should be provided during non-school hours such as late afternoon, evenings, and weekends, with privacy and non-medical services. Healthcare service providers should be staff members specifically selected and trained to work with youth.

\section{3) Family Support System}

The family was only one subsystem in the support network that would be involved and used to develop a model of youth reproductive healthcare service utilization. In general, students who are concerned about their 
parents' reactions thought that their parents did not accept their pregnancies. The present study found that youths who were concerned about their parents' reactions tended to solve their problems by themselves. The baseline data showed that $73.3 \%$ sought an illegal abortion which does not require parental consent. Otherwise, youths who did not have open communication with their families were more likely to engage in high-risk behaviors, such as using over-the-counter abortive methods or illegal services, than those who had open communication with their families. Parents are the essential change agents for their youth. Communication eventually assists parents in expressing their concerns and approval of certain health behaviors of their children.

Therefore, parents should strive for open communication with young people in order to understand their problems and to provide appropriate advice about seeking safe reproductive healthcare services (Jaccard, Dodge and Dittus, 2002). For this reason, family should be a source of information to guide young people toward safe healthcare services.

\section{DISCUSSION AND CONCLUSION}

This study indicated that the factors concerning the management of reproductive health service include the following: personal expense, communication within family, fear of parents' reactions, bureaucratic process of healthcare services, limitation of healthcare services, and healthcare providers. The six factors are then reduced into three systems to explain the important factors to consider in the management of reproductive health service, including systems of personnel, service and family support.

However, because this study offers guidelines for the management of government-run reproductive healthcare service, it does not guarantee that these factors will lead to success for every government agency. Success depends on managerial efficiency, and suitable techniques and environmental factors must be prepared for each situation.

\section{LIMITATION}

Participants in this study were all students at vocational schools. Therefore, the results of this study cannot be generalized for the use of reproductive healthcare services by the entire population, and further research should be conducted on a varied group of adolescents that includes out-of-school adolescents.

\section{ACKNOWLEDGEMENTS}

This study supported in part by Khon Kaen University, Khon Kaen, Thailand. We also acknowledge with appreciation Prof. Dr. Thongphon Promsaka Na Sakolnakorn for the helpful suggestions and comments on this research article, and would especially like to express our thanks to all the participants who so kindly participated in this study.

\section{REFERENCES}

1. Brindis, C.D., Klein, J., Schlitt, J., Santelli, J., Juszczak, L. and Hystrom, R. 2003. School-based health centers: accessibility and accountability. Journal of Adolescence Health, 32, 98-107.

2. Creel, L.C. and Perry, R.J. 2002. Improving the quality of reproductive health care for young people. New Perspectives on Quality of Care, 4, 1-8.

3. Deepasert, H. 2006. Several Problem of Teenager, Kom Chud Luek Newspaper, December 16, Page 8.

4. Dickson, K.E., Ashson, J. and Smith, J.M. 2007. Does setting adolescent-friendly standards improve the quality of care in clinics: evidence from South Africa. International Journal for Quality in Health Care, 19, 80-89.

5. Fatusi, P.O. 2005. Adolescent sexual and reproductive health need in Nigeria: shaping a pragmatic and effective response. Journal of Community Medicine \& Prymary Health Care, 17, 1-6.

6. Fothergill, K. and Ballard, E. 1998. The school-linked health center: a promising model of communitybased care for adolescents. Journal of Adolescence Health, 23, 29-38. 
7. Hitt, M. A., Bierman, L., Shimizu, K., and Kochhar, R. 2001. Direct and moderating effects of human capital on strategy and performance in professional service firms: A resource-based perspective. Academy of Management Journal, 44, 13-29.

8. Hull, T.H., Hasmi, E. and Widyantoro, N. 2004. Peer educator Initiatives for adolescent reproductive health in Indonesia. Reproductive Health Matters, 12(23), 29-39.

9. Intaraprasert, S. and Pattarachai, S. 2006. Teens' problems in modern society: unplanned and unwanted pregnancy. $1^{\text {st }}$ ed. The royal college of Thai pediatricians, Bangkok: Beyond Enterprise.

10. Jaccard, J., Dodge, T. and Dittus, P.1. 2002. Parent-adolescent communication about sex and birth control: a conceptual framework. New Dir Child Adolescence Development, 97, 9-41.

11. Kamnaunsilpa, P. 2004. Aging in the Mekong and its implication for development. Paper presented at Aging in The Mekong and Its Implication for Development, Khon Kaen, Thailand.

12. Kanchanajitra, C. et al. 2004. Thai health 2003. Institute for Population and Social Resaerch, Mahidol University and Thai Health Promotion Foundation. Bangkok: Amarin Printing and Publishing.

13. Lear, J.G. 2003. School and adolescent health: strengthening services and improving. Journal of Adolescent Health, 31(6), 310-320.

14. Olukoya, A.A., Kaya, A., Ferguson, B.J. and AbouZahr, C. 2001. Unsafe abortion in adolescents. International Journal of Gynecology and Obstetrics, 2001, 75, 137-147.

15. Poonkhum, Y. 2003. Providing adolescent-friendly reproductive health services: the Thai experience. In: Bott, S., Jejeebhoy, S., Shah, I., Puri, C., eds. Towards adulthood: exploring the sexual and reproductive health of adolescents in South Asia. Geneva: WHO.

16. Reproductive Health Division. 2006. Standard of service and reproductive health for adolescents: In the project on development of health services and reproductive health for adolescents. Bangkok: Ministry of Public Health, Thailand.

17. Ruangkanchanasert, S., Mahachoklertwattana, P. 2006. Teens' problems in modern society. $1^{\text {st }}$ ed. The Royal College of Thai Pediatricians. Bankok: Beyond Enterprise. [in Thai].

18. Warakamin, S., Boonthai, N. and Tangcharoensathien, V. 2004. Induced abortion in Thailand: current situation in public hospital and legal perspective. Reproductive Health Matters, 12, 147-56.

19. WHO. 2007a. Unsafe abortion: global and regional estimates of the incidence of unsafe abortion and associated mortality in 2003. 5th ed. Geneva: World Health Organization, p. 6-19.

20. WHO. 2007b. Adolescent pregnancy unmet needs and undone deeds: a review of the literature and program. Geneva: World Health Organization, p. 11-15. [Date of access 2007 September 9]. Available from URL: http://www.whqlibdoc.who.int/publication

21. Yamane, T. 1973. Statistics: an introductory analysis. $3^{\text {rd }}$ edition. New York: Harper Row.

22. Yongpanichkul, S. 2007. A review of sexuality and reproductive health and rights in Thailand. Hanoi: The Ford Foundation Office for Vietnam and Thailand. 